\title{
Volar Percutaneous Fixation of Recent Fracture Scaphoid
}

\author{
MOHAMED E. ELMOGHANY, M.Sc.; MOHAMED H. NAGY, M.D.; MOHAMED M. HOSNY, M.D. and \\ AL-SAYED M. AL-FORSE, M.D.
}

The Department of Orthopaedic Surgery, Faculty of Medicine, Tanta University

\begin{abstract}
Background: Scaphoid fracture is the most commonly fractured carpal bone, frequently results from a fall on an outstretched hand with the wrist in extension. The principal treatment methods are cast immobilization or surgery.

Aim of Study: The aim of this study is to evaluate results of volar percutaneous fixation of recent fracture scaphoid.

Patients and Methods: In this prospective study, 21 cases with closed scaphoid fractures were treated with volar percutaneous fixation by Herbert screw. Clinical and radiological data were analyzed.

Results: These cases were assessed according to modified mayo scoring system. Clinical results were graded as excellent, good, fair as follows: Excellent in 17 patients $(8 \%)$, good in 3 patients (14\%), fair in one patients $(5 \%)$ the excellent and good results were considered as satisfactory results while the unsatisfactory included the fair results. Thus, satisfactory results were found in 20 patients $(95 \%)$, and the unsatisfactory results were found in one patient $(5 \%)$.

Conclusion: This study proves that fixation of recent scaphoid fractures result in predictable satisfactory union rate and functional outcome.
\end{abstract}

Key Words: Volar - Scaphoid - Percutaneous fixation.

\section{Introduction}

SCAPHOID fracture is the most commonly fractured carpal bone, frequently results from a fall on an outstretched hand with the wrist in extension $[1,2]$. Most scaphoid fractures occur in active men, often athletes, in their twenties or thirties [3] Approximately $70 \%$ of scaphoid fractures occur at the waist (middle third) of the bone [4] .

Scaphoid is cashew shaped bone that articulates with five surrounding bones (radius, lunate, capitates, trapezoid and trapezium) and there is rela-

Correspondence to: Dr. Mohamed E. Elmoghany,

The Department of Orthopaedic Surgery, Faculty of Medicine, Tanta University tively poor blood supply to the proximal pole which receives blood flow in a retrograde manner from branches of the radial artery so fracture may disrupt this tenuous blood supply, leading to delayed union, nonunion, or avascular necrosis which result in arthritis and carpal collapse $[\mathbf{5 , 6 ]}$.

Early treatment of scaphoid fractures is important in preventing these complications. The principal treatment methods are cast immobilization or surgery [2].

These fractures are usually considered stable and have a tendency to heal with conservative treatment in a thumb Spica cast for 8 to 12 weeks however, this may be rejected by the young, active population desiring to participate in professional or sports-related activities or for social reasons. Moreover, cast immobilization has disadvantages such as stiffness, decreased hand grip, non-union and Malunion [4].

Open surgery or percutaneous screw fixation are other treatment options. Percutaneous screw fixation of the scaphoid was first reported by Streli in 1970 [7]. It allows more rapid return to work and sports activities.

Percutaneous screw fixation avoid devascularization of the scaphoid and division of the carpal ligaments [8-10] although Potential points of entry for fixation devices are limited by approximately $80 \%$ of the surface of the scaphoid bone being covered with articular cartilage [5]. And the boat shape of the scaphoid, requiring special skills from the surgeon to maneuver a wire or a fixation device along the true central axis of the scaphoid [11] .

The aim of this study is to evaluate results of volar percutaneous fixation of recent fracture scaphoid. 


\section{Patients and Methods}

\section{A- Patients:}

This study included 21 patients (15 males, 6 females and their ages range from 21 years to 50 years with an average of 35.5) treated between October 2017 and October 2018 (including followup period) at Tanta University Hospital with volar percutaneous fixation method. The period of followup ranged from six to 12 months with an average of 8.6 months.

\section{Clinical examination:}

\section{General examination:}

Blood pressure, pulse,temperature, respiration other body systems. Associated injuries.

\section{Local examination:}

A- Inspection: Deformity, skin condition and presence of wound or associated injuries.

$B$ - Palpation: Skin temperature, anatomical snuffbox tenderness (ASB); scaphoid tubercle tenderness (ST); pain on Longitudinal Compression of the Thumb (LCT) Fig. (1) [12].

The inclusion criteria were patient age is above the age of 18 , scaphoid waist fracture, less than one month, closed fracture ,non displaced or minimally displaced less than $2 \mathrm{~mm}$. While, the main exclusion criteria were nonunited, comminuted, proximal pole fractures, more than one month fracture, open fracture, displaced fracture (more than $2 \mathrm{~mm}$ ), cyst or sclerosis.
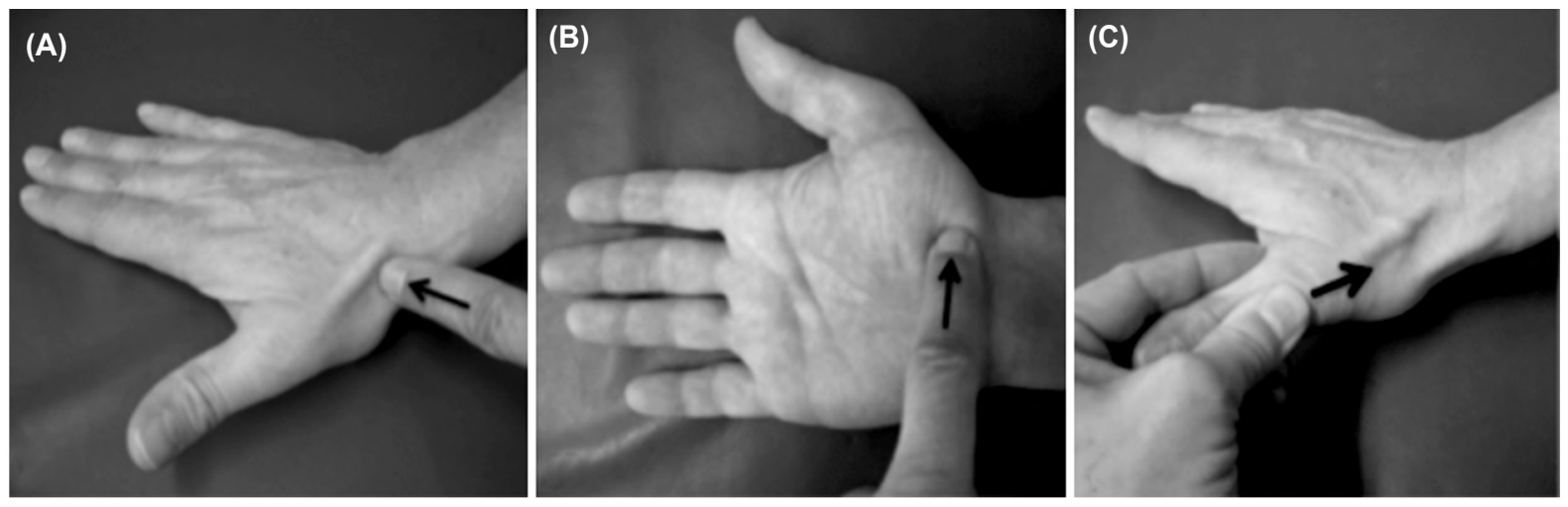

Fig. (1): The three classic clinical tests for scaphoid fracture. (A) Anatomical snuffbox tenderness (ASB); (B) Scaphoid tubercle tenderness (ST); (C) Pain on Longitudinal Compression of the Thumb (LCT) [12]

\section{B- Method:}

We performed all cases through volar approach; this technique was based on the work of Slade et al., [13] with some modifications. Firstly Under general or regional anesthesia, patient was placed supine on the operating table and the volar scaphotrapezial joint was identified. Displaced fractures were reduced under fluoroscopy in a position of Hyperextension and ulnar deviation of the wrist accompanied by thumb traction facilitated any necessary reduction of the fracture. Hyperextension assisted in bringing the trapezium dorsal to the insertion point of the guide wire, at the scaphoid tubercle. Ulnar deviation of the wrist also slide the scaphoid out from the radial styloid process. Secondly a guide wire was introduced by free-hand under fluoroscopy and placed into the distal scaphoid along the central axis. Confirm its position under multiple views. The wire was directed across the fracture and then to the center of the proximal pole and stopped at far cortex. Thirdly a transverse $5 \mathrm{~mm}$ skin incision was made around the guide wire entry and then, a blunt dissection down to the distal pole of the scaphoid. The length was assessed by using a depth gauge or by using a wire of the same length and measuring the differences. A screw of $4 \mathrm{~mm}$ less than the actual measure was chosen to ensure that the screw will be well buried in the distal cortex and will not impinge the proximal cortex. Then the wire was further advanced across the proximal pole to prevent loss of the position of the wire after reaming around it. Fourthly a cannulated drill was inserted around the wire and advanced across the fracture site and stopped short of the far cortex under. A self-tapped Herbert screw was inserted in a free-hand manner. the compression of the fracture site was identified. The distal end of the screw was buried beneath the surface.

Period of immobilization varies according to the presence of associated injury, 6 weeks for cases of ipsilateral distal radius fractures ( 2 cases), rest of cases immobilized for two weeks in below elbow slab. 


\section{Results}

Follow-up period ranged from 6 to 12 months with a mean of 7.24 months. The patients were followed-up until they achieved complete fracture healing and almost normal wrist function.

\section{A- Clinical (functional) results:}

According to mayo modified wrist scoring systems for scaphoid fracture the clinical results were graded as excellent in 17 patients $(81 \%)$, good in 3 patients $(14 \%)$, fair in one patients $(5 \%)$ Fig. (2).

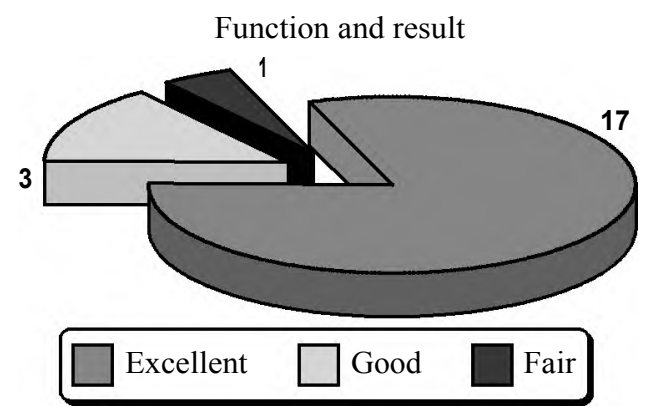

Fig. (2): Functional end results.

Pain, range of movement, return toprevious activity and grip strength:

By the end of the follow-up period 18 patients $(85 \%)$ had no pain at all 3 patients $(15 \%)$ had mild occasional pain.

Eighteen patients $(85 \%)$ regained wrist range of motion with flexion \& extention greater than 120 degrees, two patients $(10 \%)$ regained motion between 119 to 110 degree, and one patient (5\%) regained motion between 60 to 90 degrees.

Twenty patients $(95 \%)$ return to pre-fracture work status and one patient $(5 \%)$ did not return to pre-fracture work status due to continuous pain or stiffness of the wrist.

Nineteen patients $(90 \%)$ have $90 \%$ to $100 \%$ grip strength compared to the normal side, one (5\%) patient has $75 \%$ to $89 \%$ grip strength compared to the normal side, one $(5 \%)$ patient has $50 \%$ to $74 \%$ grip strength compared to the normal side.

Factors affecting the final clinical score:

1- Age:

Results showed to be statistically significant, as $p$-value $=0.0153$.
2-Associated lower end radius fracture:

Significant correlation was found. $p$-value $=$ 0.0013 .

\section{3-Position of the screw:}

Significant correlation was found between central position of the screw and the functional end results. $p$-value .0021 .

Sex, associated medical condition, mode of trauma, type of fracture, time elapsed before surgery and smoking don't affect on the final clinical score.

Union:

As regard time of fracture to union range from (6-12 week) mean 7.714, STDV 1.792. Time from injury to surgery it range from (1-30 days), mean 8.86, STDV 8.17. Time of follow-up range from (6-12 month) mean 7.24, STDV 1.84. Time of postoperative immobilization range from (2-6 week) mean 2.38 STDV 1.20.

\section{Factors affecting the time of union:}

1- Smoking: Significant correlation was found between smoking and time of fracture union. $p$ value $=0.00034$

2- Position of screw: Significant correlation was found between central position of the screw and the time of union results. $p$-value .002 .

Age, sex, associated medical condition, mode of trauma, type of fracture, time elapsed before surgery and don't affect on the final clinical score.

The complication were Malposition of Herbert screw, screw protrusion and reflex sympathetic osteodystrophy. There was no wound infection, no nonunion, no loosening of screw.

\section{Cases:}

40 years old man works as driver fall on outstretched hand. his fracture was classified as B2. Percutaneous Herbert screw was inserted 1 day after the injury. The patient was immobilized for 2 weeks and the fracture united 6 weeks later. Functional outcome at final follow-up was excellent. 

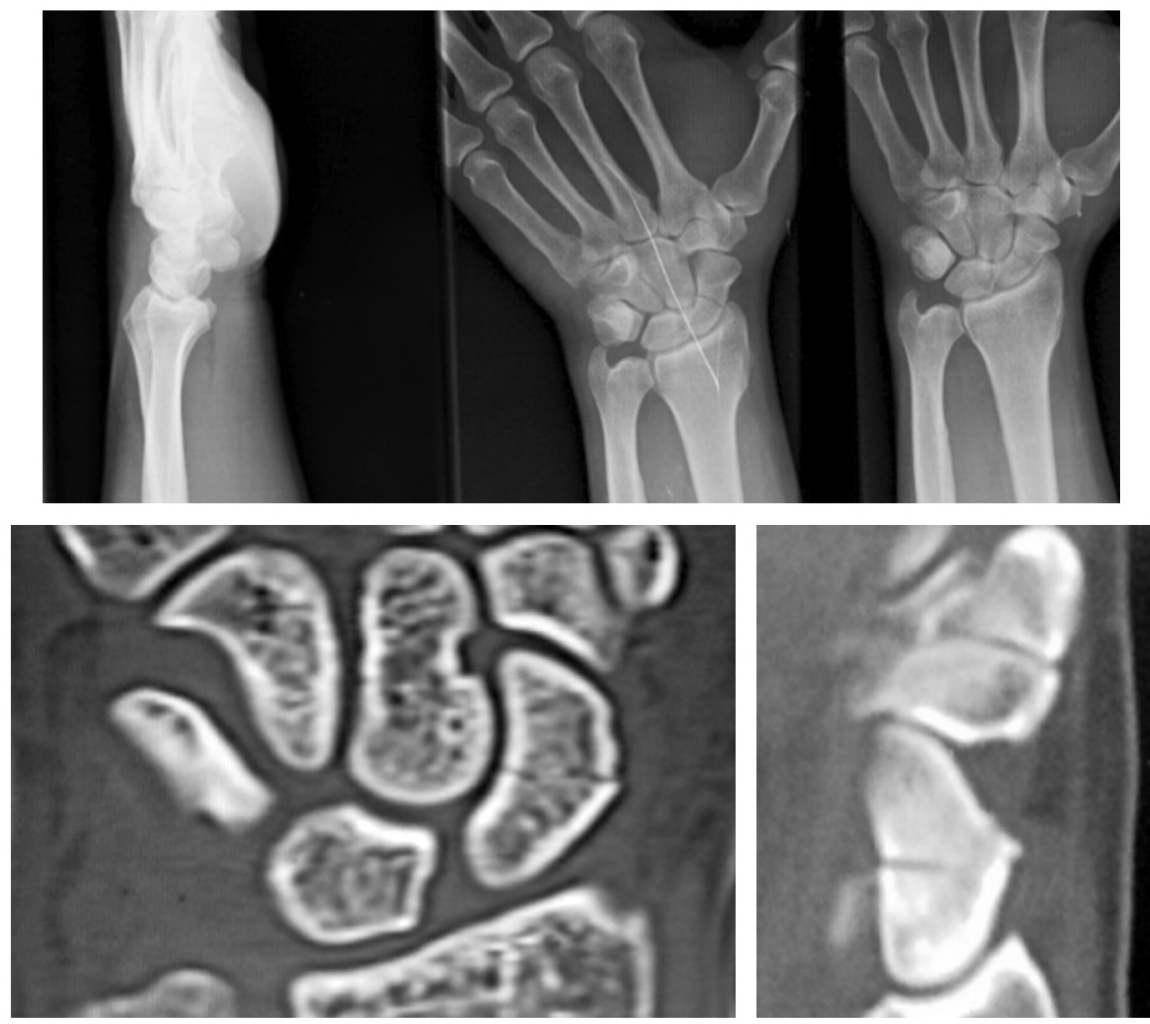

Fig. (3): Pre-operative X-ray AP and LAT views \& CT of the fracture.
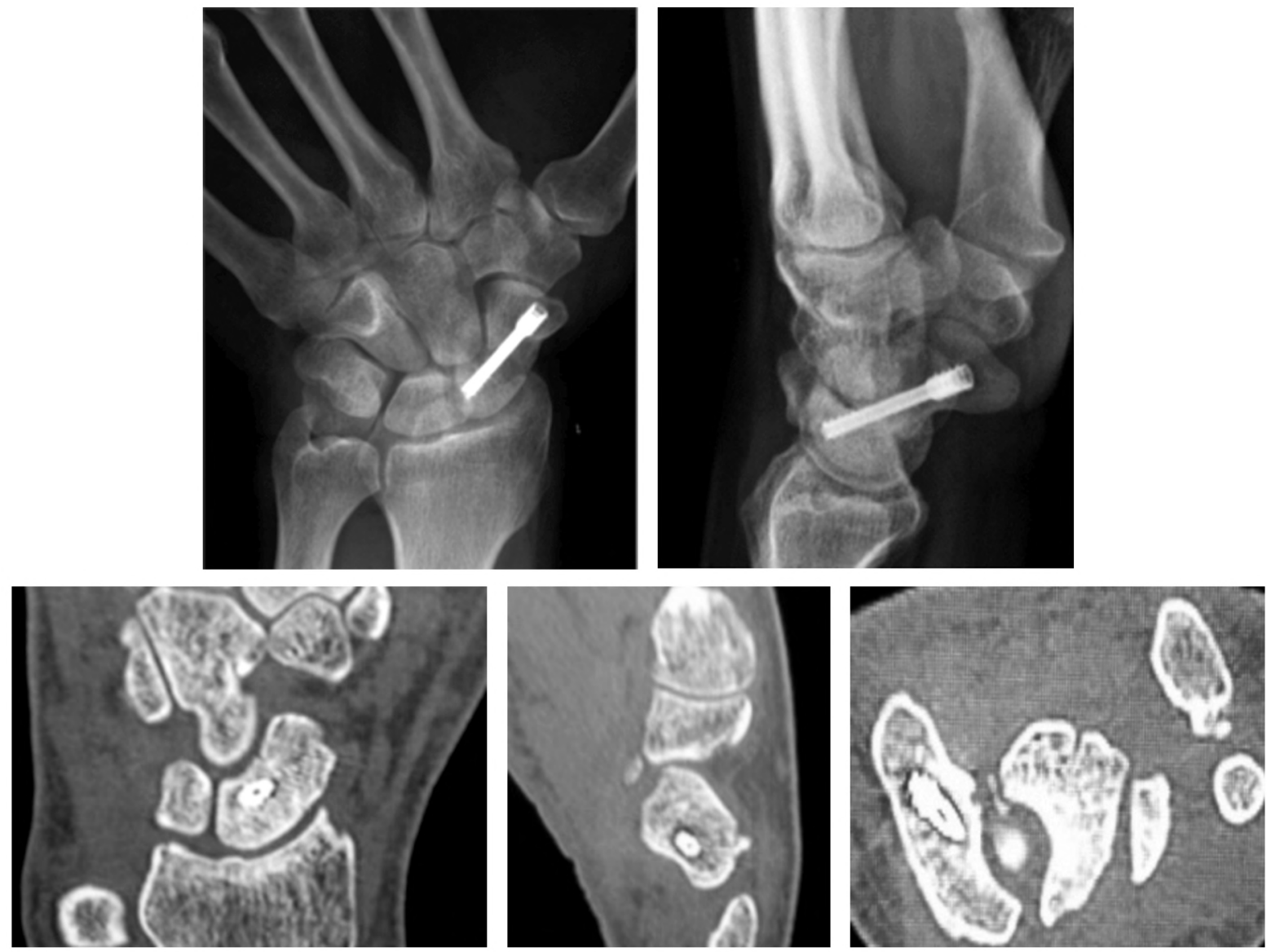

Fig. (4): Follow-up X-ray AP and LAT view after 6 months with complete union and no complication. 

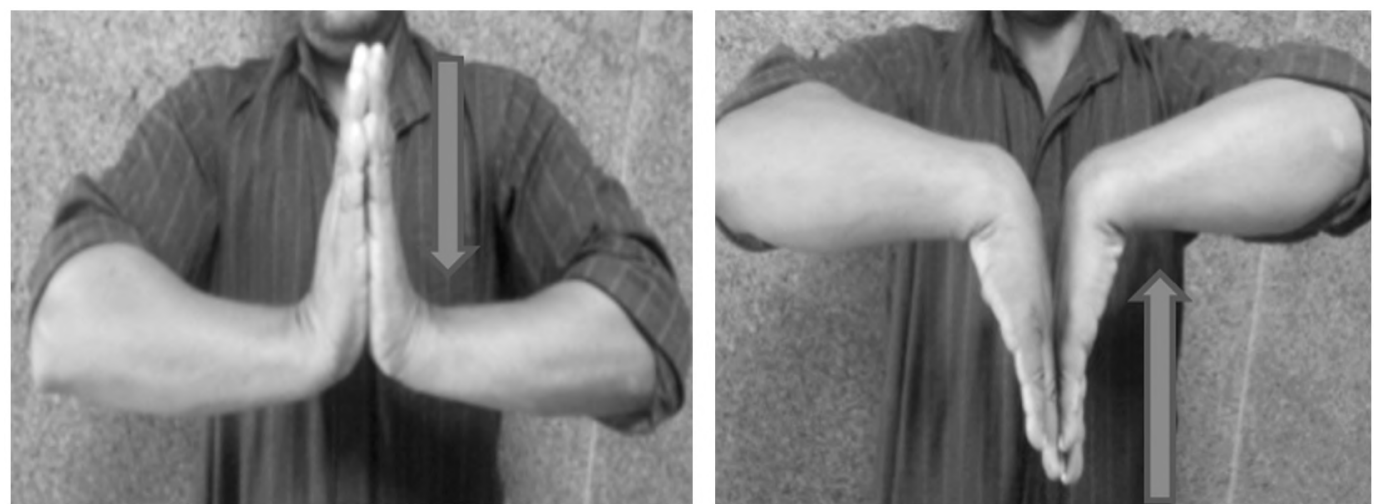

Fig. (5): Follow-up after 6 weaks show range of motion.

\section{Discussion}

Non displaced fractures of the scaphoid waist were managed with immobilization as standard treatment, with possible consequent restriction of wrist mobility. Also long cast immobilization, represent a significant socioeconomic burden [4]

Immobilization may be needed for up to 3 months, and patient compliance is thus often unsatisfactory, especially in the presence of low symptom levels, when plasters may be discarded early, resulting in delayed union or nonunion $[14,15]$

Adolfsson et al., [16] compared outcomes of percutaneous fixation with immobilization in a long scaphoid cast. Results showed a significantly better Range of Motion (ROM) in the fixation group but no differences in union rate or grip strength.

Bond et al., [17] compared percutaneous fixation with immobilization in a long scaphoid cast. All fractures achieved union. Analysis showed significant reduction in time to union in the fixation group and time to return to full duty in the fixation group.

Drac and Manak [18] proved that Cast group had significantly more non unions $(p=0.024)$ and restricted ROM and grip strength $(p / 0.0001)$.

Bongers et al., and Papaloizos et al., [19,14] favored operative treatment over cast treatment, reporting improvements in ROM, union rates and return to manual work; however, the studies provide limited quality of evidence due to the nature of the study design.

As regarding the study of Majeed, Haroon [6] Cast treatment has the disadvantages of longer immobilization time, joint stiffness, reduced grip strength, and longer time to return to manual work.
Percutaneous fixation is aimed at reducing damage to the blood supply and soft tissues, allowing early mobilization of the wrist and early return to manual work. The best available evidence for percutaneous screw fixation versus cast treatment suggests that percutaneous fixation allows a faster time to union by 7 weeks and an earlier return to manual work by 8 weeks, with similar union rates.

Inoue and Shionoya, [20] found significantly quicker return to manual work and union rate in the percutaneous fixation group than in the cast group. All fractures united in the percutaneous fixation group; there was one nonunion in the cast group.

Percutaneous screw fixation may be done by dorsal or volar approaches and many studies were done to find out which one is the best but it still controversial until now [21].

Regarding the use of the percutaneous technique for the treatment of recent and delayed scaphoid waist fractures, Wozasek and Moser [22] proved that Bony healing was achieved in $81.8 \%$ after a mean of 82 months. However, it seems logical to use an open technique for the treatment of delayed scaphoid fractures because a bone graft is required.

In this study 21 patient with fracture from (130) days old were fixed percutaneously by Herbert screws through volar approach and followed-up for a minimum of 6 months and maximum of 12 months. The average time for union is 7.71. Weeks. Return to work ranged from 14 to 45 days depending on the patients occupation and return to active sports from 6 to 12 week.

Haddad et al., [23]. Revealed that union was obtained in all at a mean of 57 days and patients were able to return to sedentary work within four days and to manual work within five weeks. 
D. Cecilia-López [24], revealed that the fracture healed in all cases after a mean follow-up of 7 weeks.

Iacobellis et al., [25], revealed that all fractures achieved radiographic union at an average of 57 days and return to work ranged from 18 to 40 days depending on the patient's occupation, and return to active sports ranged from 49 to 70 days.

With our practice in this work we found that with usage of the volar approach it is easy to identify the bony land marks, maintain the reduction during the procedure and easy interpretation of the fluoroscopically obtained image and it is difficult to introduce a guide wire through the long axis of the scaphoid and it is required several times of trials and needs learning curve.

In this study age was found to have statistically significant effect in the end results of our study. Most studies did not mention that the age had evident effect on the results.

In this study, smoking also was found to affect time of union as nonsmokers showed rapid healing than smokers. Haddad et al., [23] Iacobellis et al., [25] confirmed that. Patients should be advised regarding the bad effect of tobacco use.

In this study, significant correlation was found between central position of the screw and satisfactory functional end results and rapid union, this result with The study of trumble et al., [26] .

In addition the biomechanical study of McAdams et al., [27] in the cadaveric model confirmed that the central placement of a screw in the proximal fragment had superior results compared with those of eccentric screw position.

Regarding volar screw placement, controversy exists about whether to enter through the trapezium or avoid it. The data suggest that, the transtrapezial approach reliably achieves central positioning of a screw in the proximal and distal poles. [28] we avoid the transtrapezial approach in our study to save scaphotrapezium joint.

Also, the choice of the screw to use for fixation is a topic of debate. Herbert screws, headless compression screws, $3.5-\mathrm{mm}$ cannulated screws, and Acutrak screws have been used.

Shaw [29] and Rankin et al., [30] showed that there were greater compression forces with the cannulated screw, but accepted the biological advantages of the headless Herbert screw, which can be buried within the scaphoid without disrupting its bony architecture.

Newport et al., [31] found better compression with the Herbert screw. Haddad FS [32] found that Acutrak screw have some of the advantages of the Herbert screw in being headless, having a variable pitch, and also providing improved inter fragmentary compression.

Adla et al., [33] found no significant difference in compressive effects between the Herbert screw and the Acutrak screw. However, there is general agreement that central screw placement determines fixation and compression at the fracture site, regardless of the type of screw used for fixation [26]

Compared to the study of Adolfsson et al., [16] the complication were nonunion, reflex sympathetic dystrophy.

In general, this study emphasizes the clinical success and low complication associated with volar percutaneous fixation the fracture scaphoid, so percutaneous fixation is more suitable over cast immobilization or open surgery, the relatively small sample size and the absence of control group are limitation to this study.

\section{References}

1- ALSHRYDA S., SHAH A., ODAK S., AL-SHRYDA J., ILANGO B. and MURALI SR.: Acute fractures of the scaphoid bone: Systematic review and meta-analysis. Vol. 10, Surgeon, p. 218-29, 2012

2- GARCIA R.M. and RUCH D.S.: Management of scaphoid fractures in the athlete: Open and percutaneous fixation. Sports Med. Arthrosc. [Internet]., 22 (1): 22-8, 2014.

3- DUCKWORTH A.D., JENKINS P.J., AITKEN S.A., CLEMENT N.D., COURT-BROWN C.M. and McQUEEN M.M.: Scaphoid Fracture Epidemiology. J. Trauma. Inj. Infect. Crit. Care [Internet], 72 (2): 1, 2011.

4- COONEY W.P., DOBYNS J.H. and LINSCHEID R.L.: Fractures of the scaphoid: A rational approach to management. Clin. Orthop. Relat. Res., (149): 90-7, 1980.

5- PATTERSON R., MORITOMO H., YAMAGUCHI S., MITSUYASU H., MUNIR SHAH M.D., BUFORD W., et al.: Scaphoid anatomy and mechanics: Update and review. Vol. 13, Operative Techniques in Orthopaedics, 2-10 p., 2003.

6- MAJEED H.: Non-operative treatment versus percutaneous fixation for minimally displaced scaphoid waist fractures in high demand young manual workers. Journal of Orthopaedics and Traumatology, 239-44, 2014.

7- STRELI R. and ZENTRALBL CHIR: [Percutaneous screwing of the navicular bone of the hand with a compression drill screw (a new method)]. Sep., 95 (36): 106078, 1970. 
8- BEEK M., ABOLMAESUMI P., LUENAM S., ELLIS R.E., SELLENS R.W. and PICHORA D.R.: Validation of a new surgical procedure for percutaneous scaphoid fixation using intra-operative ultrasound. Med. Image Anal. [Internet], 12 (2): 152-62, 2008.

9- HEGAZY G.: Percutaneous Screw Fixation of Scaphoid Waist Fracture Non-Union Without Bone Grafting. J. Hand. Microsurg., Dec. 7, 7 (2): 250-5, 2015.

10- GEHRMANN S.V., GRASSMANN J.P., WILD M., JUNGBLUTH P., KAUFMANN R.A., WINDOLF J., et al.: Treatment of scaphoid waist fractures with the HCS screw. GMS Interdiscip. Plast. Reconstr. Surg. DGPW, 3: Doc. $10,2014$.

11- SMITH E.J., ELLIS R.E. and PICHORA D.R.: Computerassisted percutaneous scaphoid fixation: Concepts and evolution J. Wrist. Surg., 2 (4): 299-305, 2013.

12- PARVIZI J., WAYMAN J., KELLY P. and MORAN C.G.: Combining the clinical signs improves diagnosis of scaphoid fractures. A prospective study with follow-up. J. Hand. Surg. Br., 23 (3): p. 324-7, 1998.

13- SLADEJ MERRELL: Technique for percutaneous fixation of displaced and non-displaced acute scaphoid fracture and selected nonunion. J. Hand. Surg., Vol. 33a: 966-73, 2008.

14- PAPALOIZOS M.Y., et al.: Minimally invasive fixation versus conservative treatment of undisplaced scaphoid fractures: A cost effectiveness study. J. Hand. Surg. Br., 29 (2): 116-9, 2004.

15- BARTON N.J.: Twenty questions about scaphoid fractures. J. Hand. Surg. Br., 17 (3): 289-31, 1992.

16- ADOLFSSON L., LINDAU T. and ARNER M.: Acutrak screw fixation versus cast immobilization for undisplaced scaphoid waist fractures. J. Hand. Surg. Br., 26 (3): 192$5,2001$.

17- BOND C.D., SHIN A.Y., MCBRIDE M.T. and DAO K.D.: Percutaneous screw fixation or cast immobilization for nondisplaced scaphoid fractures. J. Bone. Joint. Surg. Am., 83: 483-e8, 2001.

18- DRAC P., MANAK P. and LABONEK I.: Percutaneous osteosynthesis versus cast immobilization for the treatment of minimally and non-displaced scaphoid fractures. Functional outcomes after a follow-up of at least 12 month. Biomed. Pap., 32 (2): 152-5, 2005.

19- BONGERS K.J. and PONSEN R.J.: Operative and nonoperative management of fractures of the carpal scaphoid: Five years' experience. Neth. J. Surg., 32 (4): 142-5, 1980.

20- INOUE G. and SHIONOYA K.: Herbert screw fixation by limited access for acute fractures of the scaphoid. J. Bone. Joint. Surg. Br., May, 79 (3): 418-e21, 1997.
21- JEON I.H., MICIC I.D., OH C.W., PARK B.C. and KIM P.T.: Percutaneous Screw Fixation for Scaphoid Fracture: A Comparison Between the Dorsal and the Volar Approaches. J. Hand. Surg. Am., 34 (2): 228-37, 2009.

22- WOZASEK G.E. and MOSER K.D.: Percutaneous screw fixation for fracture of the scaphoid. J. Bone. Joint. Surg. Br. Jan., 73 (1): 138-e42, 1991.

23- HADDAD F.S. and GODDARD N.J.: Day case acute percutaneous scaphoid fixation Journal of Hand Surgery: European Volume, 22, P. 25, 1997.

24- CECILIA-LÓPEZ, D. SUÁREZ-ARIAS, L. JARA-SÁNCHEZ and F. RESINES-ERASUN.: Revista Española de Cirugía Orthopedic Traumatology (English Edition), v. 53 pages: 364-70, 2012.

25- IACOBELLIS C., BALDAN S. and ALDEGHERI R.: Percutaneous screw fixation for scaphoid fractures, Musculoskeletal Surgery, Vol 95, p. 199-203, 2014.

26- TRUMBLE, CLARKE and KREDER: Nonunion of the scaphoid, treatment with cannulated screws compared with Herbert screw. J. Bone. Joint. Surg., 78A: 1829-37, 1996.

27- CHAN K.W. and McADAMS T.R.: Central screw placement in percutaneous screw scaphoid fixation: A cadaveric comparison of proximal and distal techniques. J. Hand. Surg. Am. Jan., 29 (1): 74-e9, 2004.

28- MEERMANS G., VAN GLABBEEK F., BRAEM M.J., VAN RIET R.P., HUBENS G. and VERSTREKEN F.: Comparison of two percutaneous volar approaches for screw fixation of scaphoid waist fractures: Radiographic and biomechanical study of an osteotomy simulated model. J. Bone. Joint. Surg. Am., 96 (16): 1369-76, 2014.

29- SHAW J.A.: A biomechanical comparison of scaphoid screws. J. Hand. Surg. Am., 12 (3): 347-53, 1987.

30- RANKIN G., KUSCHNER S.H., ORLANDO C., MCKELLOP H., BRIEN W.W. and SHERMAN R.: A biomechanical evaluation of a cannulated com-pressive screw for use in fractures of the scaphoid. J. Hand. Surg. Am., 16 (6): 1002-10, 1991.

31- NEWPORT M.L., WILLIAMS C.D. and BRADLEY W.D.: Mechanical strength of scaphoid fixation. J. Hand. Surg. Br., 21 (1): 99-102, 1996.

32- HADDAD F.S. and GODDARD N.J.: Acute percutaneous scaphoid fixation: A pilot study. J. Bone Joint Surg. Br., 80 (1): 95-9, 1998.

33- ADLA D.N., KITSIS C. and MILES A.W.: Compression forces generated by mini bone screws: A comparative study done on bone model. Injury, 36 (1): 65-70, 2005. 


\section{التثبيت عبر الجلد عن طريق باطن الربغ الزوريخ

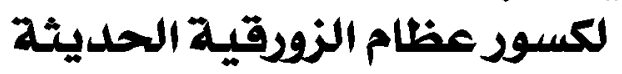

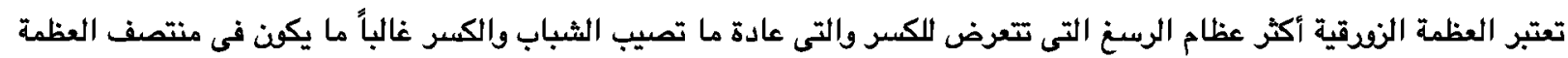

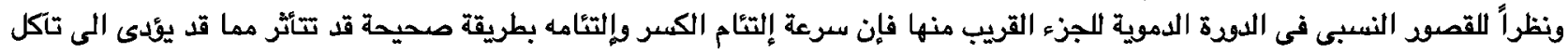

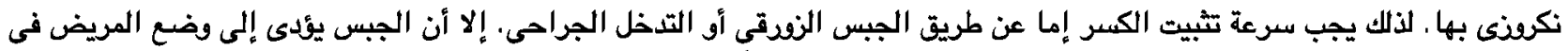

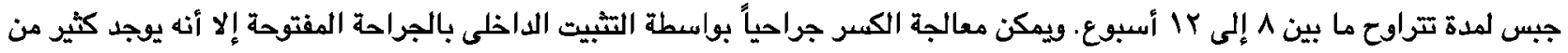
السلبيات لهذه الطريقة، لذلك أتجهت الأنظار إلى التثيت عن طريق الجلد ويعتبر التبيت عن طريق الجلد من الطرق المفضلة حيث أنه يتفادى حدوث خلل بأربطة الرسغ.

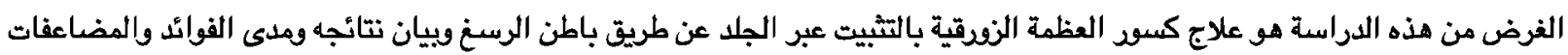

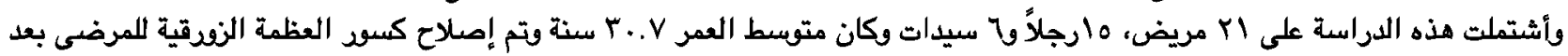

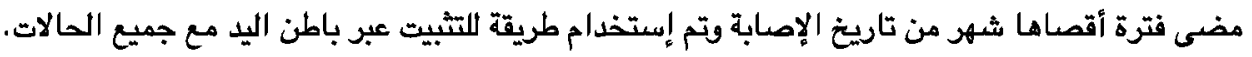

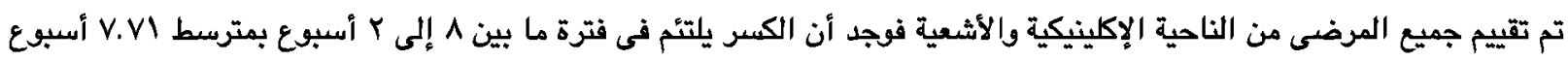

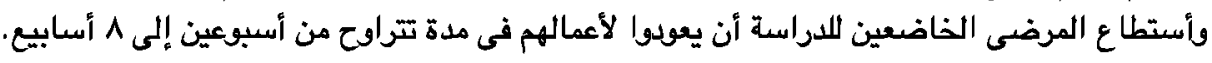
تم تقييم نتائج الدراسة بواسطة تقييم *مايو* لوظائف الرسخ فكانت (ممتازة في VV حالة، جيدة فى كاحالات، مقبولة فى حالة).

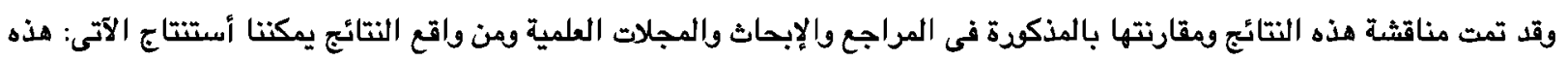

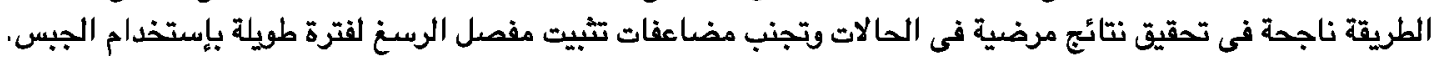

